\title{
ПРОБЛЕМЫ УСТАНОВЛЕНИЯ И РЕАЛИЗАЦИИ УГОЛОВНОЙ ОТВЕТСТВЕННОСТИ ЗА ФИКТИВНУЮ РЕГИСТРАЦИЮ (ПОСТАНОВКУ НА УЧЕТ) ПО МЕСТУ ПРЕБЫВАНИЯ ИЛИ ПО МЕСТУ ЖИТЕЛЬСТВА В ЖИЛОМ ПОМЕЩЕНИИ В РОССИЙСКОЙ ФЕДЕРАЦИИ
}

\section{Борисов С.В.}

Аннотация: В ст. 322 УК РФ предусмотрена ответственность за фиктивную регистрацию гражданина Российской Федерации по месту пребывания или по месту жстельства в жилом помещуении в Российской Федерацчии и фиктивную регистрацию иностранного гражданина или лицуа без гражданства по месту жительства в жилом помещуении в Российской Федерации, а в ст. 322 УК РФ - за фиктивную постановку на учет иностранного гражданина или лица без гражданства по месту пребывания в жилом помещуении в Российской Федерации. Для достижения цуели и решения задач, стоящуих перед исследованием были применены общенаучные и частно-научные методы: анализ, синтез, структурно-логическийметод, статистический и иные методы научного познания. С последним предложением корреспондирует завериающий критерий криминализации, заключающийся в том, что таковая не должна производиться, если борьба с данным вредным для общества деянием возможна и эффективна при помощи иных, более мягких мер. Считаем, что более эффективным и последовательным было бы установление административной ответственности за фиктивную регистрацию (постановку на учет) по месту пребывания или по месту жительства, а уголовно-правовой запрет изелесообразно было увязать с административной преюдицией и (или) определенным количеством совериенных действий по такой регистрации (постановке на учет). Ключевые слова: Уголовная ответственность, теория уголовного права, ужесточение уголовной ответственности, фиктивность, критерии криминализации, общественная опасность деяния, административная ответственность, преступления, законодатель, суд.

В своем послании Федеральному Собранию 12 декабря 2012 г. Президент России В.В. Путин подчеркнул необходимость ужесточения ответственности за незаконную миграцию и нарушения в сфере регистрационного учета.
29 декабря 2012г. в Государственную Думу Федерального Собрания Российской Федерации главой государства был внесен законопроект, предусматривающий введение уголовной и административной ответственность за 
нарушение правил регистрации по месту жительства и по месту пребывания. Несмотря на критические замечания, высказанные Общественной палатой Российской Федерации и Советом при Президенте Российской Федерации по развитию гражданского общества [1], соответствующий Федеральный закон был принят Госдумой практически в неизменном виде, 21 декабря 2013 г. подписан Президентом Российской Федерации и вступил в силу с 3 января 2014 г.[2] Именно данный Закон дополнил Особенную часть Уголовного кодекса Российской Федерации статьями $322^{2}$ и $322^{3}$ об ответственности за фиктивную регистрацию (постановку на учет) по месту пребывания или по месту жительства в жилом помещении в Российской Федерации.

В ст. $322^{2}$ УК РФ предусмотрена ответственность за фиктивную регистрацию гражданина Российской Федерации по месту пребывания или по месту жительства в жилом помещении в Российской Федерации и фиктивную регистрацию иностранного гражданина или лица без гражданства по месту жительства в жилом помещении в Российской Федерации, а в ст. $322^{3}$ УК РФ - за фиктивную постановку на учет иностранного гражданина или лица без гражданства по месту пребывания в жилом помещении в Российской Федерации. В качестве основной причины криминализации данных действий называется значительное количество адресов, по которым граждане регистрируются фиктивно, то есть без намерения реально проживать в соответствующих помещениях. По данным ФМС России в 2011 г. было зафиксировано более 6400 таких адресов, по которым было зарегистрировано почти 300000 граждан. В последующие два года эти показатели возросли в 1,5 раза. В конце 2013 г. таких адресов насчитывалось уже свыше 10000 , а количество зарегистрированных по ним граждан, в том числе и иностранных, оценивается более чем в 500 миллионов человек, что более чем в 3 раза превышает численность населения России. Вследствие этого у регистрирующих органов отсутствует возможность направлять необходимые и достоверные данные в налоговые органы, военные комиссариаты, судебные органы, также затруднен учет иностранных граждан [3]. Вместе с тем приведенные данные указывают лишь на распространенность соответствующих деяний, что является только одним из необходимых критериев (принципов) установления уголовной ответственности за те или иные действия. Более того, указанные числа говорят даже не о распространенности, а о массовости фактов фиктивной регистрации, что порождает вопрос о том, правильно ли определена отраслевая принадлежность соответствующих правонарушений. Для ответа на этот вопрос следует обратиться к рассмотрению действий по фиктивной регистрации (постановке на учет) по месту пребывания или по месту жительства через призму оснований криминализации деяний, разработанных в теории уголовного права.

По этому поводу весьма справедливо отмечала Н.Ф. Кузнецова, указав, что при внесении предложений по совершенствованию действующего уголовного законодательства, прежде всего, необходимо ответить на следующие принципиальные вопросы: 1) не расширяют ли они необоснованно сферу уголовной ответственности; 2) не ужесточают ли наказание; 3) не способствуют ли они увеличению квалификационных ошибок, в том числе в силу смешения преступлений и проступков[4].

В теории уголовного права выделяются следующие принципы (критерии) криминализации деяний: 1) криминализируемое деяние должно быть общественно опасным; 2) оно должно иметь достаточную степень распространенности; 3) ожидаемые положительные последствия криминализации должны превышать ее отрицательные последствия; 4) криминализация не должна противоречить Конституции Российской Федерации, действующему праву и международным соглашениям России; 5) она не должна противоречить нормам нравственности; 6) криминализация должна быть осуществима в процессуальном и криминалистическом аспектах; 7) криминализация не должна производиться, если борьба с данным вредным для общества 
на учет) по месту пребывания или по месту

деянием возможна и эффективна при помощи иных, более мягких мер[5].

Необходимость определения общественной опасности деяния при решении вопроса о его криминализации подчеркивал в своих трудах Ю.И. Ляпунов, отмечавший, что при этом объектом познания и оценки является материальное свойство, антисоциальная направленность и вредоносная сущность человеческого поведения определенного рода или вида, изначально заключающего в себе опасность причинения вреда (ущерба) правоохраняемым благам[6].

Характер общественной опасности действий по фиктивной регистрации (постановке на учет) по месту пребывания или по месту жительства определяется на основе анализа нарушаемого ими объекта, к которому следует относить общественные отношения, обеспечивающие соблюдение установленного порядка такой регистрации (постановки на учет). Эти же общественные отношения нарушаются и многими административными правонарушениями в сфере миграционного учета, поэтому применительно к первому критерию криминализации необходимо обратить основное внимание не на характер, а на степень общественной опасности соответствующих деяний.

Изучение содержания статей $322^{2}$ и $322^{3}$ УК РФ приводит к выводу о том, что законодателю не удалось в полной мере ответить на вопрос о том, достигают ли запрещенные в них действия той степени вредоносности, при которой можно говорить о совершении именно общественно опасного деяния. Полагаем, что данный вопрос мог быть снят за счет установления административной преюдиции, при которой на общественную опасность содеянного указывала бы повторность совершаемого правонарушения, а равно посредством определения количественного критерия, касающегося минимального числа фактов фиктивной регистрации (постановки на учет). В настоящее время состав преступления образует даже первый факт совершения такого действия, причем без учета того, сколько лиц было фиктивно зарегистрировано (поставлено жительства.

Второй критерий криминализации связан с распространенностью соответствующих деяний. Как уже было отмечено выше, фиктивная регистрация (постановка на учет) по месту пребывания или по месту жительства, осуществленная на основе документов, содержащих заведомо ложные сведения, без намерения фактически проживать (пребывать) в соответствующем жилом помещении либо без намерения предоставить такое помещение для проживания (пребывания), в Российской Федерации является массовым явлением. Поэтому заявление о том, что данное обстоятельство вызывает необходимость установления именно уголовной ответственности за такие действия, можно сравнить с такой же позицией относительно курения либо распития спиртных напитков в общественных местах, обладающих еще большей распространенностью. Кроме того, факты фиктивной регистрации далеко не всегда связаны со «злым умыслом», поскольку они могут быть обусловлены желанием формально соблюсти требования для устройства на работу, прохождения лечения и т.д. Именно необходимость соблюдения формальных требований является поводом для регистрации (постановки на учет) по месту пребывания или по месту жительства, тогда как мобильность населения в современных условиях все более возрастает и не вполне «укладывается» в существующий порядок миграционного учета. Между тем в ч. 1 ст. 27 Конституции Российской Федерации указывается: «Каждый, кто законно находится на территории Российской Федерации, имеет право свободно передвигаться, выбирать место пребывания и жительства». Данное конституционное положение имеет прямое действие, но до настоящего времени отсутствуют полноценные разъяснения Конституционного Суда РФ по его содержанию применительно к современным условиям.

Третий критерий установления уголовной ответственности связан с тем, что ожидаемые положительные последствия криминализации 
должны превышать ее отрицательные последствия. Применительно к рассматриваемым деяниям позволим себе предположить, что их криминализация не вызовет ожидаемый положительный эффект, поскольку реализация уголовной ответственности в данном случае сопряжена с рядом трудностей, обусловленных не только массовостью таких нарушений правил миграционного учета, но еще и значительными трудностями в их выявлении и доказывании. Риск понести уголовную ответственность, пусть даже и минимальный, лишь повысит «тарифы» на рынке соответствующих противоправных «услуг», усилит его коррумпированность и организованность.

Следующим критерием криминализации выступает подтверждение того, что она не должна противоречить Конституции Российской Федерации, действующему праву и международным соглашениям России. Выше нами уже указывалось положение Конституции Российской Федерации, гарантирующее свободу передвижения, выбора места жительства или места пребывания, с которым идет вразрез всестороннее ужесточение ответственности за несоблюдение формальных требований миграционного учета, особенно касающихся граждан Российской Федерации. Это же положение закреплено в ст. 13 Всеобщей декларации прав человека[7] и в ст. 12 Международного пакта о гражданских и политических правах[8], причем в последней делается следующая оговорка: «Упомянутые выше права не могут быть объектом никаких ограничений, кроме тех, которые предусмотрены законом, необходимы для охраны государственной безопасности, общественного порядка, здоровья или нравственности населения или прав и свобод других и совместимы с признаваемыми в настоящем Пакте другими правами». Конечно же, формальные требования относительно регистрации (постановки на учет) по месту пребывания или месту жительства не лишают человека права на свободу передвижения и выбор места жительства или места пребывания, однако затрудняют реализацию такой свободы, поэтому каждое ограничение последней должно иметь веское основание. Миграционные правила закреплены в законах и подзаконных нормативных правовых актах и носят характер предписаний, а значит, подлежат обязательному исполнению, однако это вовсе не означает, что уклонение от их соблюдения следует относить к предмету именно уголовно правового регулирования.

Касательно такого критерия криминализации как отсутствие противоречий с нормами нравственности можно отметить, что такие нормы не являются формализованными, чтобы в деталях касаться правил миграционного учета, однако определенным индикатором в данном случае может служить общественное мнение. В связи с этим нами были изучены форумы в сети Интернет, связанные с обсуждением введения уголовной ответственности за фиктивную регистрацию (постановку на учет) по месту пребывания или по месту жительства. Данное изучение показало явное преобладание негативных отзывов, что, безусловно, нельзя рассматривать как выражение мнения всего общества, однако это позволяет констатировать наличие быстрой и однозначной негативной реакции общественности на соответствующие новеллы уголовного законодательства. Ни для кого не секрет, что отклонение от требований о регистрации (постановке на учет) по месту пребывания или по месту жительства большинством населения не воспринимается как общественно опасное поведение, подлежащее уголовному преследованию. Поэтому при криминализации тех или иных деяний в сфере миграционного учета следует выделять именно наиболее опасные проявления последних, существенно нарушающие установленный порядок регистрации (постановки на учет) по месту пребывания или по месту жительства, что должно однозначно вытекать из содержания соответствующих уголовно-правовых норм.

Еще одним критерием для криминализации выступает то, что она должна быть осуществима в процессуальном и криминалистическом аспектах. В первую очередь речь идет и реальной возможности выявления и доказывания 
обозначен момент окончания предусмотренных

признаков тех или иных деяний. Относительно фиктивной регистрации (постановки на учет) по месту пребывания или по месту жительства процесс доказывания осложняется многоуровневой бланкетностью соответствующих уголовно-правовых норм. Так, для применения ст. $322^{2}$ УК РФ необходимо обратиться к Закону РФ от 25 июня 1993 г. № 5242-I «О праве граждан Российской Федерации на свободу передвижения, выбор места пребывания и жительства в пределах Российской Федерации»[9], Федеральному закону от 25 июля 2002г. № 115-Ф3 «О правовом положении иностранных граждан в Российской Федерации»[10] и Федеральному закону от 18 июля 2006г. № 109-Ф3 «О миграционном учете иностранных граждан и лиц без гражданства в Российской Федерации»[11], регламентирующим порядок регистрации российских и иностранных граждан по месту жительства и по месту пребывания. Кроме того, следует учитывать положения, закрепленные в Правилах регистрации и снятия граждан Российской Федерации с регистрационного учета по месту пребывания и по месту жительства в пределах Российской Федерации[12], в Административном регламенте предоставления Федеральной миграционной службой государственной услуги по регистрационному учету граждан Российской Федерации по месту пребывания и по месту жительства в пределах Российской Федерации[13], в Административном регламенте предоставления Федеральной миграционной службой государственной услуги по осуществлению миграционного учета в Российской Федерации[14] и в Правилах осуществления миграционного учета иностранных граждан и лиц без гражданства в Российской Федерации[15]. При этом следует обращать внимание на производимые изменения и дополнения данных нормативных правовых актов, выделять ту их редакцию, которая действовала на момент совершения деяния, а равно последующие ее изменения, устраняющие преступность соответствующих действий.

Кроме того, в содержании диспозиций рассматриваемых статей УК РФ недостаточно четко в них преступлений и не уточнен их субъект, а равно отсутствует дифференциация уголовной ответственности с учетом количества фактов фиктивной регистрации (постановки на учет) по месту пребывания или по месту жительства.

Поскольку изучаемые преступления имеют формальную конструкцию состава, они должны рассматриваться как оконченные с момента завершения оформления фиктивной регистрации (постановки на учет) по месту пребывания или по месту жительства в жилом помещении в Российской Федерации. То есть момент окончания преступления связан с документальным оформлением факта регистрации или постановки на учет. Фактический и юридический моменты окончания общественно опасного деяния в данном случае совпадают и связаны именно с фиктивной регистрацией (постановкой на учет), а не с последующим существованием документального подтверждения последней.

В диспозициях статей $322^{2}$ и $322^{3}$ УК РФ не говорится о дальнейших действиях (бездействии), связанных с существованием факта фиктивной регистрации (постановки на учет) по месту пребывания (месту жительства), поэтому рассматриваемые преступления не следует относить к категории длящихся. Поскольку постановка на учет (регистрация) по месту пребывания (месту жительства) признается фиктивной, то есть не имеющей юридического значения, то последовавшее за этим фактическое проживание гражданина Российской Федерации без регистрации или постановки на учет, проживание на территории России без регистрации иностранного гражданина или лица без гражданства следует расценивать как незаконные, влекущие административную ответственность по ст. 19.15.1 либо ст. 18.8 Кодекса Российской Федерации об административных правонарушениях[16], но не как длящуюся фиктивную регистрацию (постановку на учет).

В связи с указанными обстоятельствами срок давности уголовной ответственности следует исчислять с момента оформления 
фиктивной регистрации (постановки на учет). При этом следует учитывать положение, закрепленное в ч. 1 ст. 10 УК РФ, исключающее обратную силу уголовного закона, устанавливающего уголовную ответственность, а именно не применять статьи $322^{2}$ и $322^{3}$ УК РФ к лицам, совершившим запрещенные ими действия до их вступления в силу.

Между тем на практике встречаются случаи осуждения за преступления, запрещенные рассматриваемыми статьями, совершенные до их вступления в силу. Так, по приговорам мирового судьи судебного участка № 113 района Преображенское г. Москвы граждане К. и Л. осуждены за деяния, предусмотренные ст. $322^{3}$ УК РФ, совершенные ими в январе-октябре 2013г.[17], тогда как данная статья была введена в УК РФ Федеральным законом от 21 декабря 2013г. Считаем, что эти и подобные судебные решения не учитывают указанное выше положение ст. 10 УК РФ.

В статьях $322^{2}$ и $322^{3}$ УК РФ не содержатся признаки, конкретизирующие субъекта этих преступлений, в связи с чем такую конкретизацию следует производить за счет анализа признаков объективной стороны соответствующих преступлений. Так, субъектом преступления, предусмотренного ст. $322^{2}$ УК РФ, могут выступать достигшие 16-тилетнего возраста: гражданин Российской Федерации, иностранный гражданин или лицо без гражданства, представившие заведомо недостоверные сведения или документы для постановки на учет (регистрацию), либо вставшие на учет (зарегистрировавшиеся по месту пребывания (жительства) без намерения пребывать (проживать) в соответствующем жилом помещении, или собственник (наниматель) жилого помещения, поставивший на учет (зарегистрировавший) указанных лиц без намерения предоставить им это жилое помещение для пребывания (проживания). Уголовную ответственность по ст. $322^{2}$ УК РФ, по нашему мнению, несет и служащий ФМС, поставивший на учет (зарегистрировавший) гражданина Российской Федерации по месту пребывания (месту жительства), а равно иностранного гражданина или лицо без гражданства - по месту жительства на основе представленных заведомо недостоверных сведений или документов. В преступлении, предусмотренном ст. $322^{3}$ УК РФ, субъектом преступления является достигшие 16-тилетнего возраста иностранный гражданин или лицо без гражданства, представившие заведомо недостоверные (ложные) сведения или документы, либо вставшие на учет по месту пребывания без намерения пребывать (проживать) в нем, а равно лицо, формально выступающее принимающей стороной, не имеющее намерения предоставить эти помещения для пребывания (проживания).

При квалификации преступления, предусмотренного ст. $322^{3}$ УК РФ, возникает вопрос о необходимости учета примечания к ст. 18.9 КоАП РФ, согласно которому в случае нарушения приглашающей или принимающей стороной либо должностным лицом юридического лица, обеспечивающего обслуживание иностранного гражданина или лица без гражданства либо выполняющего обязанности, связанные с соблюдением условий пребывания в Российской Федерации или транзитного проезда через ее территорию иностранных граждан или лиц без гражданства, установленного порядка оформления документов на право пребывания иностранных граждан и лиц без гражданства в Российской Федерации, их проживания, передвижения, изменения места пребывания или жительства в Российской Федерации и выезда за ее пределы в отношении двух и более приглашенных либо принимаемых иностранных граждан и (или) лиц без гражданства административная ответственность, установленная данной статьей, наступает в отношении каждого иностранного гражданина или лица без гражданства в отдельности. Применительно же к деянию, предусмотренному ст. $322^{3}$ УК РФ, такой подход означает, что при совершении фиктивной постановки на учет двух и более иностранных граждан или лиц без гражданства, уголовная ответственность должна наступать с учетом каждого из них, то есть за совокупность соответствующего числа престу- 
плений. Это же положение может быть отнесено и к юридической оценке деяний, запрещенных ст. $322^{2}$ УК РФ. Полагаем, что однозначный ответ на данный вопрос возможен только на законодательном уровне за счет дифференцированного подхода к запрету одного, двух или более фактов фиктивной регистрации (постановки на учет).

С последним предложением корреспондирует завершающий критерий криминализации, заключающийся в том, что таковая не должна производиться, если борьба с данным вредным для общества деянием возможна и эффективна при помощи иных, более мягких мер. Считаем, что более эффективным и последовательным было бы установление административной ответственности за фиктивную регистрацию (постановку на учет) по месту пребывания или по месту жительства, а уголовно-правовой запрет целесообразно было увязать с административной преюдицией и (или) определенным количеством совершенных действий по такой регистрации (постановке на учет).

Таким образом, изучение статей $322^{2}$ и $322^{3}$ УК РФ об ответственности за преступления об ответственности за фиктивную регистрацию (постановку на учет) по месту пребывания или по месту жительства в жилом помещении в Российской Федерации и практики их применения позволило нам очертить круг имеющихся проблем, обусловленных недостаточной, на наш взгляд, научной проработкой оснований криминализации данных деяний, и неточностями законодательной техники, допущенными при определении кримообразующих признаков последних. Устранение данных проблем возможно только на законодательном уровне, оперативное же воздействие на правоприменительную практику могло бы оказать соответствующее постановление Пленума Верховного Суда Российской Федерации.

\section{Библиография:}

1. Филимонов А. Меры по борьбе с «резиновыми квартирами» и фиктивной регистрацией граждан // Система «ГАРАНТ»: http://www.garant.ru/article/522528/\#ixzz2xEyI0dyG (дата обращения: 20 июня 2014г.).

2. Федеральный закон от 21 декабря 2013г. № 376-Ф3 «О внесении изменений в отдельные законодательные акты Российской Федерации» // Собрание законодательства Российской Федерации. 2013. № 51. Ст. 6696.

3. Кузнецова Н.Ф. Проблемы квалификации преступлений. Лекции по спецкурсу «Основы квалификации преступлений» / Науч. ред. и предисл. В.Н. Кудрявцева. М.: Издательский Дом «Городец», 2007. С. 189-190.

4. Курс российского уголовного права. Общая часть / Под ред. В.Н. Кудрявцева, А.В. Наумова. M., 2001. C. 22.

5. Ляпунов Ю.И. Общественная опасность как универсальная категория советского уголовного права. М., 1989. С. 4.

6. Всеобщая декларация прав человека (принята на третьей сессии Генеральной Ассамблеи ООН резолюцией 217 А (III) от 10 декабря 1948 г.) // Российская газета. 1998. 10 декабря.

7. Международный пакт о гражданских и политических правах (Нью-Йорк, 19 декабря 1966 г.) // Сборник действующих договоров, соглашений и конвенций, заключенных с иностранными государствами, вып. XXXII. М., 1978.

8. Закон РФ от 25 июня 1993 г. № 5242-I «О праве граждан Российской Федерации на свободу передвижения, выбор места пребывания и жительства в пределах Российской Федерации» // Ведомости Съезда народных депутатов и Верховного Совета Российской Федерации. 1993. № 32. Ст. 1227. 
9. Федеральный закон от 25 июля 2002г. № 115-Ф3 «О правовом положении иностранных граждан в Российской Федерации» // Собрание законодательства Российской Федерации. 2002. №30. Ст. 3032.

10. Федеральный закон от 18 июля 2006 г. № 109-Ф3 «О миграционном учете иностранных граждан и лиц без гражданства в Российской Федерации» // Собрание законодательства Российской Федерации. 2006. № 30. Ст. 3285.

11. Постановление Правительства РФ от 17 июля 1995 г. № 713 «Об утверждении Правил регистрации и снятия граждан Российской Федерации с регистрационного учета по месту пребывания и по месту жительства в пределах Российской Федерации и перечня должностных лиц, ответственных за регистрацию» // Собрание законодательства Российской Федерации. 1995. № 30 Ст. 2939.

12. Приказ Федеральной миграционный службы от 11 сентября 2012 г. № 288 «Об утверждении Административного регламента предоставления Федеральной миграционной службой государственной услуги по регистрационному учету граждан Российской Федерации по месту пребывания и по месту жительства в пределах Российской Федерации» // Российская газета. 2013. 17 апреля.

13. Приказ Федеральной миграционной службы (ФМС России) от 29 августа 2013 г. № 364 «Об утверждении Административного регламента предоставления Федеральной миграционной службой государственной услуги по осуществлению миграционного учета в Российской Федерации» // Российская газета. 2013. 1 ноября.

14. Постановление Правительства РФ от 15 января 2007 г. № 9 «О порядке осуществления миграционного учета иностранных граждан и лиц без гражданства в Российской Федерации» // Собрание законодательства Российской Федерации. 2007. № 5. Ст. 653.

15. Приговоры мирового судьи судебного участка № 113 района Преображенское г. Москвы от 20 февраля 2014г. по уголовным делам № 1-07/14 и № 1-08/14 // Интернет-сайт «Ваше реальное право»: http://real-pravo.com/publ/prigovor_imenem_rossijskoj_federacii_po_st_322_ 3 uk_rf/1-1-0-58/1-1-0-59 (дата обращения: 22 июня 2014г.).

\section{References (transliterated):}

1. Filimonov A. Mery po bor'be s «rezinovymi kvartirami» i fiktivnoi registratsiei grazhdan // Sistema «GARANT»: http://www.garant.ru/article/522528/\#ixzz2xEyI0dyG (data obrashcheniya: 20 iyunya 2014g.).

2. Federal'nyi zakon ot 21 dekabrya 2013g. № 376-FZ «O vnesenii izmenenii v otdel'nye zakonodatel'nye akty Rossiiskoi Federatsii» // Sobranie zakonodatel'stva Rossiiskoi Federatsii. 2013. № 51. St. 6696.

3. Kuznetsova N.F. Problemy kvalifikatsii prestuplenii. Lektsii po spetskursu «Osnovy kvalifikatsii prestuplenii» / Nauch. red. i predisl. V.N. Kudryavtseva. M.: Izdatel'skii Dom «Gorodets», 2007. S. 189-190.

4. Kurs rossiiskogo ugolovnogo prava. Obshchaya chast' / Pod red. V.N. Kudryavtseva, A.V. Naumova. M., 2001. S. 22.

5. Lyapunov Yu.I. Obshchestvennaya opasnost' kak universal'naya kategoriya sovetskogo ugolovnogo prava. M., 1989. S. 4.

6. Vseobshchaya deklaratsiya prav cheloveka (prinyata na tret'ei sessii General'noi Assamblei OON rezolyutsiei 217 A (III) ot 10 dekabrya 1948 g.) // Rossiiskaya gazeta. 1998. 10 dekabrya.

7. Mezhdunarodnyi pakt o grazhdanskikh i politicheskikh pravakh (N'yu-Iork, 19 dekabrya 1966 g.) // Sbornik deistvuyushchikh dogovorov, soglashenii i konventsii, zaklyuchennykh s inostrannymi gosudarstvami, vyp. XXXII. M., 1978. 
8. Zakon RF ot 25 iyunya 1993 g. № 5242-I «O prave grazhdan Rossiiskoi Federatsii na svobodu peredvizheniya, vybor mesta prebyvaniya i zhitel'stva v predelakh Rossiiskoi Federatsii»// Vedomosti S'ezda narodnykh deputatov i Verkhovnogo Soveta Rossiiskoi Federatsii. 1993. № 32. St. 1227.

9. Federal'nyi zakon ot 25 iyulya $2002 \mathrm{~g}$. № $115-\mathrm{FZ}$ «O pravovom polozhenii inostrannykh grazhdan v Rossiiskoi Federatsii» // Sobranie zakonodatel'stva Rossiiskoi Federatsii. 2002. №30. St. 3032.

10. Federal'nyi zakon ot 18 iyulya 2006 g. № 109-FZ «O migratsionnom uchete inostrannykh grazhdan i lits bez grazhdanstva v Rossiiskoi Federatsii» // Sobranie zakonodatel'stva Rossiiskoi Federatsii. 2006. № 30. St. 3285.

11. Postanovlenie Pravitel’stva RF ot 17 iyulya 1995 g. № 713 «Ob utverzhdenii Pravil registratsii i snyatiya grazhdan Rossiiskoi Federatsii s registratsionnogo ucheta po mestu prebyvaniya i po mestu zhitel'stva v predelakh Rossiiskoi Federatsii i perechnya dolzhnostnykh lits, otvetstvennykh za registratsiyu» // Sobranie zakonodatel'stva Rossiiskoi Federatsii. 1995. № 30 St. 2939.

12. Prikaz Federal’noi migratsionnyi sluzhby ot 11 sentyabrya 2012 g. № 288 «Ob utverzhdenii Administrativnogo reglamenta predostavleniya Federal'noi migratsionnoi sluzhboi gosudarstvennoi uslugi po registratsionnomu uchetu grazhdan Rossiiskoi Federatsii po mestu prebyvaniya i po mestu zhitel'stva v predelakh Rossiiskoi Federatsii» // Rossiiskaya gazeta. 2013. 17 aprelya.

13. Prikaz Federal'noi migratsionnoi sluzhby (FMS Rossii) ot 29 avgusta 2013 g. № 364 «Ob utverzhdenii Administrativnogo reglamenta predostavleniya Federal'noi migratsionnoi sluzhboi gosudarstvennoi uslugi po osushchestvleniyu migratsionnogo ucheta v Rossiiskoi Federatsii» // Rossiiskaya gazeta. 2013. 1 noyabrya.

14. Postanovlenie Pravitel'stva RF ot 15 yanvarya 2007 g. № 9 «O poryadke osushchestvleniya migratsionnogo ucheta inostrannykh grazhdan i lits bez grazhdanstva v Rossiiskoi Federatsii» // Sobranie zakonodatel'stva Rossiiskoi Federatsii. 2007. № 5. St. 653.

15. Prigovory mirovogo sud'i sudebnogo uchastka № 113 raiona Preobrazhenskoe g. Moskvy ot 20 fevralya 2014g. po ugolovnym delam № 1-07/14 i № 1-08/14 // Internet-sait «Vashe real'noe pravo»: http://realpravo.com/publ/prigovor_imenem_rossijskoj_federacii_po_st_322_3 uk_rf/1-1-0-58/1-1-0-59 (data obrashcheniya: 22 iyunya 2014g.). 